\title{
Longitudinal observation of anxiety and depression among palliative care cancer patients
}

\author{
Corinna Sewtz $^{1}$, Wiebke Muscheites ${ }^{1}$, Christina Grosse-Thie ${ }^{1}$, Ursula Kriesen ${ }^{1}$, Malte Leithaeuser ${ }^{1,2}$, \\ Dietrich Glaeser ${ }^{1,3}$, Philipp Hansen ${ }^{1}$, Guenther Kundt ${ }^{4}$, Georg Fuellen ${ }^{4}$, Christian Junghanss ${ }^{1}$ \\ ${ }^{1}$ Department of Medicine, Clinic III - Hematology, Oncology, Palliative Medicine, Rostock University Medical Center, Rostock, Germany; ${ }^{2}$ Internal \\ Medicine Private Practice, Rostock, Germany; ${ }^{3}$ Medical Clinic III, Hematology, Oncology, Hemostaseology, Palliative Care and Complementary \\ Medicine, Rostock Südstadt Hospital, Germany; ${ }^{4}$ Institute for Biostatistics and Informatics in Medicine and Ageing Research, Rostock University \\ Medical Center, Germany \\ Contributions: (I) Conception and design: C Junghanss, C Sewtz, W Muscheites; (II) Administrative support: U Kriesen, C Grosse-Thie, D Glaeser; \\ (III) Provision of study materials or patients: U Kriesen, C Grosse-Thie; (IV) Collection and assembly of data: C Sewtz, W Muscheites; (V) Data \\ analysis and interpretation: C Junghanss, C Sewtz, G Kundt; (VI) Manuscript writing: All authors; (VII) Final approval of manuscript: All authors. \\ Correspondence to: Dr. med. Corinna Sewtz. Department of Medicine, Clinic III - Hematology, Oncology, Palliative Medicine, Rostock University \\ Medical Center, Ernst-Heydemann-Strasse 6, 18057 Rostock, Germany. Email: corinna.sewtz@uni-rostock.de.
}

Background Anxiety and depressive symptoms are commonly reported to have a high prevalence in advanced cancer patients. However, whether the severity of the symptoms change during a stay in a palliative care unit (PCU) and after discharge home has not been studied thus far. This prospective, longitudinal, single-center study screened for anxiety and depression as measured on the German version of Hospital Anxiety and Depression Scale (HADS-D) in a palliative care (PC) cancer cohort at three different time points.

Methods: Consecutive patients (N=206) admitted to a PCU were evaluated of whom N=102 could be enrolled. Patients were screened for anxiety and depression using the HADS-D questionnaire: $24 \mathrm{~h}$ after admittance (P1), within 24 h before discharge (P2) and 2 weeks after discharge (P3). Longitudinal changes and influencing factors were determined.

Results: Nearly $80 \%$ of all patients had at least at one time point a HADS score $\geq 8$ indicating a clinically meaningful symptom burden. The P1 mean scores were $7.1 \pm 3.3$ (anxiety) and $8.9 \pm 4.6$ (depression). Depression was associated with underlying cancer type $(\mathrm{P}<0.05)$. Anxiety and depression stabilized during hospitalization $(\mathrm{P} 2)$. However, a significant deterioration after discharge (P3) was observed (anxiety $\mathrm{P}=0.046$; depression $\mathrm{P}=0.003$ ), in particular in older patients ( $>65$ years) and higher ECOG status $(\geq 3)$. Patients with a short time since first diagnosis ( $<1$ year) had significantly higher symptom burden compared to patients with a longer disease course. Participation was 50\% emphasizing the difficulty to study PC patients. Most patients had advanced cancers (99\%). Underlying cancer types consisted of a broad variety of solid tumors including $15 \%$ hematological cases. Median survival was 1.1 months.

Conclusions: The high prevalence of anxiety and depressive symptoms points to the need for psychological support. All PC patients should be screened for psychological distress to identify those in need of further assessment and treatment. The deterioration at home suggests the need for improved outpatient management, including home-based psychological support. Caregivers should be aware of the psychological vulnerability of newly diagnosed cancer patients, patients with lower functional status and higher age.

Keywords! Palliative care (PC); advanced cancer patients; anxiety and depression; HADS questionnaire

Submitted Jun 30, 2020. Accepted for publication Dec 14, 2020.

doi: 10.21037/apm-20-1346

View this article at: http://dx.doi.org/10.21037/apm-20-1346 


\section{Introduction}

For cancer patients entering into a palliative care (PC) setting, their quality of life (QOL) can be influenced by uncertainty, leading to psychological distress. This often causes additional suffering at the end of life (1). Psychological distress can progress with physical decline and worsening of symptoms (2,3). Anxiety and depressive symptoms are commonly reported to have a high prevalence in advanced cancer patients. The prevalence of depressive symptoms differs remarkably in different studies from $8 \%$ to $77 \%(1,4-9)$. About $50 \%$ of patients with advanced cancer meet the criteria for a psychiatric disorder, the most common being adjustment disorders (11-35\%) and major depression (5-26\%) (10). Important risk factors for the development of depression in cancer patients are previous depressive episodes in past medical or family history (11), missing social support (12), younger age, advanced disease at first diagnosis, bad functional status (13), or bad symptom control (14). Risk factors for depression in PC patients are mostly unclear, but might be similar. The end of life is often associated with worries and anxiety. The prevalence of anxiety in advanced cancer patients ranges in different studies from $11 \%$ to $63 \%$ (4-9). In addition, anxiety and depression have been shown to adversely affect QOL $(8,9)$. Depression even has been found to be an independent predictor of poor survival in patients with advanced cancer (15). Nevertheless, low rates of detection and treatment of psychological distress is still a crucial problem in PC (16). In treatment of advanced cancer patients, both psychosocial and pharmacological treatments are effective for anxiety and depression (10). Consequently, treating psychiatric conditions improves QOL in these patients (10). Taking all this into account, screening for psychological distress should be an integral part of PC. To date, a variety of screening tools to identify psychological morbidity in patients with somatic complaints are used. The Hospital Anxiety and Depression Scale (HADS) is the most widely used instrument $(7,17,18)$. The HADS has been validated for many different patient populations, as well as for PC patients $(19,20)$. Professional associations highly recommend the HADS based on objectivity, validity and reliability, including guidelines used for various somatic groups (21). A particular advantage of this questionnaire is the relatively short length (26 minutes) (18).

It should be noted that the terms "anxiety" and "depression" in these above mentioned studies are used in many ways and often include, but are not restricted to "anxiety disorder" and "major depression" as defined by DSM IV-criteria. In the present study the term "anxiety and depressive symptoms" is used in a broad sense of the word.

As described, psychological distress in terminally ill patients is a serious problem with high prevalence in those showing symptoms of anxiety and depression. The objectives of this study presented were (I) to screen for anxiety and depression using the validated German version of the HADS (HADS-D) (21) in PC patients at admission to our palliative care unit (PCU), (II) to detect changes in anxiety and depression levels measured by the HADS-D at discharge from PCU as well as two weeks afterward at home, and (III) to detect differences in the presence of anxiety and depressive symptoms with respect to sociodemographic and clinical characteristics.

We present the following article in accordance with the STROBE reporting checklist (available at http://dx.doi. org/10.21037/apm-20-1346) (22).

\section{Methods}

\section{Study design}

The PaRoLi study (Palliative Care in Rostock: Focus on Quality of Life) was conducted in a German PC cohort to screen for anxiety and depressive symptoms. The study was designed as a prospective, longitudinal, cohort survey for consecutive patients in the interdisciplinary PCU of Rostock University Medical Center and conducted in accordance with the Declaration of Helsinki (as revised in 2013). The study was approved by the institutional ethics board of Rostock University Medical Center, Germany (No.: A 2013-0028) and informed consent was taken from all the patients. The study design is displayed in Figure 1. Anxiety and depressive symptoms were assessed until $24 \mathrm{~h}$ after admission (P1), within 24 h before discharge (P2) and two weeks after discharge (P3) using the HADS-D.

\section{Patients}

From 5/2013 to $12 / 2013$ consecutive PC patients were enrolled. The last follow-up and closure of the database was in 1/2015. All patients admitted to the PCU were screened. Patients eligible for study participation included those who were at least 18 years old and received PC. A further eligibility criterion was the capability to understand and respond to study questionnaires in German. Exclusion 


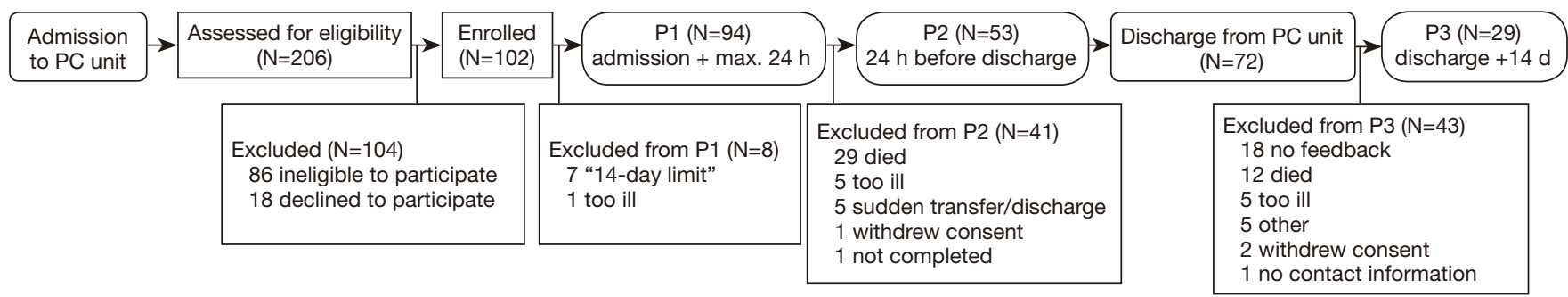

Figure 1 Study design of PaRoLi study. Anxiety and depression were assessed at three different time points: within 24 h after admission (P1), within $24 \mathrm{~h}$ before discharge (P2) and two weeks after discharge (P3) using the HADS-D.

criteria were very bad general health condition, cognitive impairment without orientation, and a "14-day limit" for interviews. The "14-day limit" was defined for re-admittances within the study period: at least 14 days should lie between two interviews to reduce the burden of study participation.

The questionnaires were completed either self-employed or in a structured interview by the study team. For patients with minor cognitive impairment matching the inclusion criteria, a form with all answer options in large writing was provided.

\section{Data collection}

Age, sex, main diagnosis, type of cancer, time since diagnosis, symptoms and ECOG performance status at admission, length of stay, and place and time of death were recorded for each patient. Type of discharge (classified into home, hospice, nursing home, other wards/hospital) as well as concomitant specialized outpatient PC after discharge was documented.

\section{Anxiety and depression (HADS-D)}

The 14-item questionnaire comprises of two seven-item subscales, measuring anxiety and depressive symptoms during the previous week (17), each item consisting of a 4-point Likert scale. Total scores for each subscale were calculated. They can range from 0 to 21 , with higher scores indicating greater distress. Scores exceeding 10 on each subscale constitute a case definition for psychological morbidity, scores of 8-10 indicate sub-clinical caseness, and scores $<8$ represent non-cases respective to the original authors (17). In PC studies different cut-off values are used $(4,7,23)$. The following definition was applied: a score $\geq 8$ indicates clinically meaningful anxiety or depression [9] as it has been shown that the balance between sensitivity and specificity regarding a cut-off of $\geq 8$ seems to be most favorable for both scales (24). For better comparison with other studies, the cut-off $\geq 11$ was also investigated. Besides, summing up of the anxiety and depression subscales, to a global score, can be evaluated for unspecific screening and progress, as anxiety and depressive symptoms develop, through common negative basic emotions. It can be used as a measure of the general mental distress in PC patients (19). According to the original authors, a global score $\geq 16$ is connected to a pronounced mental abnormality (17).

\section{Statistical analysis}

Statistical evaluation was performed using IBM SPSS Statistics 22 for Windows. Results were obtained using descriptive statistics [frequency, mean value (MV), standard deviation (SD) and median]. All quantitative characteristics were found to be non-normally distributed by the results of Kolmogorov-Smirnov tests. In addition, survival time analyses according to Kaplan-Meier were performed. Survival was calculated between study inclusion and death of the patient or closure of the database in $01 / 2015$. The test results of the HADS-D were calculated according to the instructions in the HADS-D manual (21). In the Kolmogorov-Smirnov test and Shapiro-Wilk test for normal distribution, all subscales and global scores were normally distributed except for the responses of the anxiety scale at the first and second time points. Depending on the scales Wilcoxon signed rank test and paired $t$-test were applied to detect longitudinal changes. To identify factors influencing the HADS-D results bivariate analyses ( $t$-test or MannWhitney $U$ test) were performed. To detect an influence of the diagnosis the least significant difference (LSD) test was applied. Concerning missing data we omitted those cases with the missing data and analyzed the remaining. All $\mathrm{P}$ values resulted from two-sided statistical tests and values of 
$\mathrm{P}<0.05$ were considered to be statistically significant (22).

\section{Results}

\section{Study participation}

In the study period, 206 consecutive patients were screened for eligibility. One hundred and two patients were eligible and consented to take part in the study (see Figure 1), thus the enrollment rate was $49.5 \%$. Reasons for non-attendance were death during the stay, rejection of consent, bad general health condition, or sudden discharge.

The phases of the study and reasons for non-participation are displayed in Figure 1. The actual participation rate for the first interview was $45.6 \%$ due to quick worsening of the medical condition. Fifty-two percent of study patients took part in the second interview. Of 41 sent questionnaires for the third interview, 29 were sent back (70.7\%). In $78.2 \%$ inpatient surveys were performed in the form of structured interviews, the other patients filled out the questionnaires independently.

\section{Patient characteristics and clinical course}

Patient characteristics and data of the patients' clinical course are summarized in Table 1. The average age was expectedly high with a range from middle to high age. Most study patients had a cancer diagnosis. As time since diagnosis might influence anxiety and depressive symptoms, this variable was calculated. Patients knew their cancer diagnosis on average for two years. ECOG performance status was high: $65.7 \%$ of study participants had an ECOG 3 or 4 when admitted to PCU. The mean stay was 8 days with a wide range. On average, patients were 3 days longer in hospital than in PCU. In the study period, nearly a third of the patients died in PCU, two thirds could be discharged most commonly into home. After discharge about a third (21/72) received specialized outpatient palliative care (SOPC), for patients in home care the percentage was $37.5 \%$. Mean survival after admission was 3.1 months, median survival after admission was 1.1 months. As to be expected, $92.2 \%$ of patients deceased within follow-up. Patients were most frequently married or in a partnership $(65.5 \%), 57.6 \%$ were living at home with their family.

\section{Anxiety and depression (HADS-D)}

In total, 176 HADS-D questionnaires (174 anxiety, 176 depression scores) were completed during the study period. Both, anxiety and depression screening scores were high in the analyzed cohort. Seventy-eight point seven percent of all patients had at least once a significant level of anxiety or depression $(\geq 8)$ in one of the interviews, $50.0 \%$ at a cut-off value of 11 respectively. As displayed in Figure 2 both mean sum scores showed little improvement during hospitalization $(\mathrm{P}=\mathrm{n} . \mathrm{s}$.) but significant deterioration between discharge and two weeks afterward [anxiety $(\mathrm{P}=0.046)$, depression $(\mathrm{P}=0.003)]$. Overall, both sum scores at $\mathrm{P} 3$ were higher than at $\mathrm{P} 1$ and $\mathrm{P} 2$ corresponding to an aggravation of anxiety and depressive symptoms. The global score revealed the same trend (Table S1). In a further longitudinal analysis only patients for whom questionnaires were available for all three time points were analyzed (Table 2). Results confirmed a similar symptom burden overtime as the analysis of the total cohort at each time point (Table S1). Overall, anxiety and depressive symptoms were stable during the inpatient stay, but worsened significantly at home after two weeks. This was true for all patients as well as for those patients having completed all three surveys as scheduled.

\section{Degree of anxiety and depressive symptoms}

Overall, anxiety $(52.1 \%)$ was less prevalent than depression $(73.4 \%)$, regarding $(\geq 8)$ in one of the interviews. At baseline, as measured on the HADS-D anxiety was present in $40.9 \%$, with depression in $56.7 \%$ of the patients. These rates increased over time with a relevant anxiety level in $44.8 \%$ and a clinically meaningful depression in $72.4 \%$ of the patients after discharge at home (Table S2). Hence, the proportion of conspicuous scores on both subscales increased from $\mathrm{P} 1$ to $\mathrm{P} 3$. It can also be stated that the proportion of abnormal values was higher in the outpatient than in the inpatient setting.

To identify factors potentially influencing anxiety and depressive symptoms, subsequent analyses were performed. Underlying cancer had no significant influence on the degree of anxiety (P1, P2, P3) and depression (P2, P3), although numbers were low (Table S3). However, depression values on admission were heterogeneous based on the cancer type $(\mathrm{P}<0.05)$. As displayed in Figure 3 abnormal depression scale values were more pronounced in patients suffering from gastrointestinal and urogenital cancers than patients with hematological or head-neckcancers. Age, gender, SOPC, or survival from admittance to the PCU did not influence the subscales in further analyses. 
Table 1 Demographic characteristics and clinical course of patients

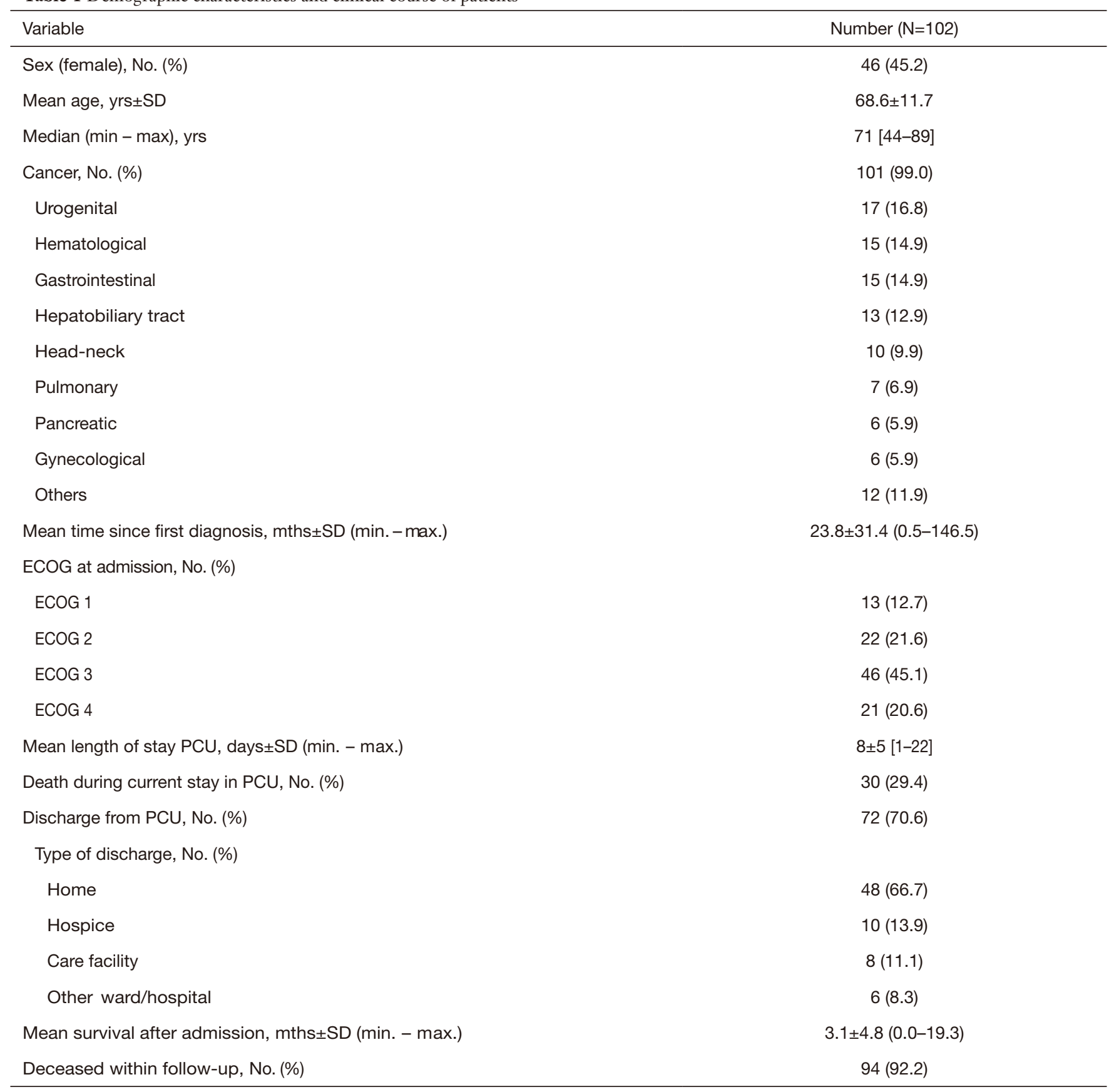

In particular cancer patients knowing only shortly their cancer diagnosis benefited from inpatient PC. Patients with first diagnosis less than 365 days ago had higher anxiety and depression scores at admission and at home $(\mathrm{P}<0.05$, both). The MVs are displayed in Table 3.

Based on the assumption that longer stays in a PCU might influence the degree of anxiety and depressive symptoms, the length of stay was analyzed accordingly (Table S4). Patients who stayed one week or less in PCU had significantly higher depression scores $(\mathrm{P}=0.032)$ at home. Accordingly, a longer stay on PCU was nonsignificantly associated with less anxiety and depressive symptoms two weeks afterward.

There was no significant difference between the results 

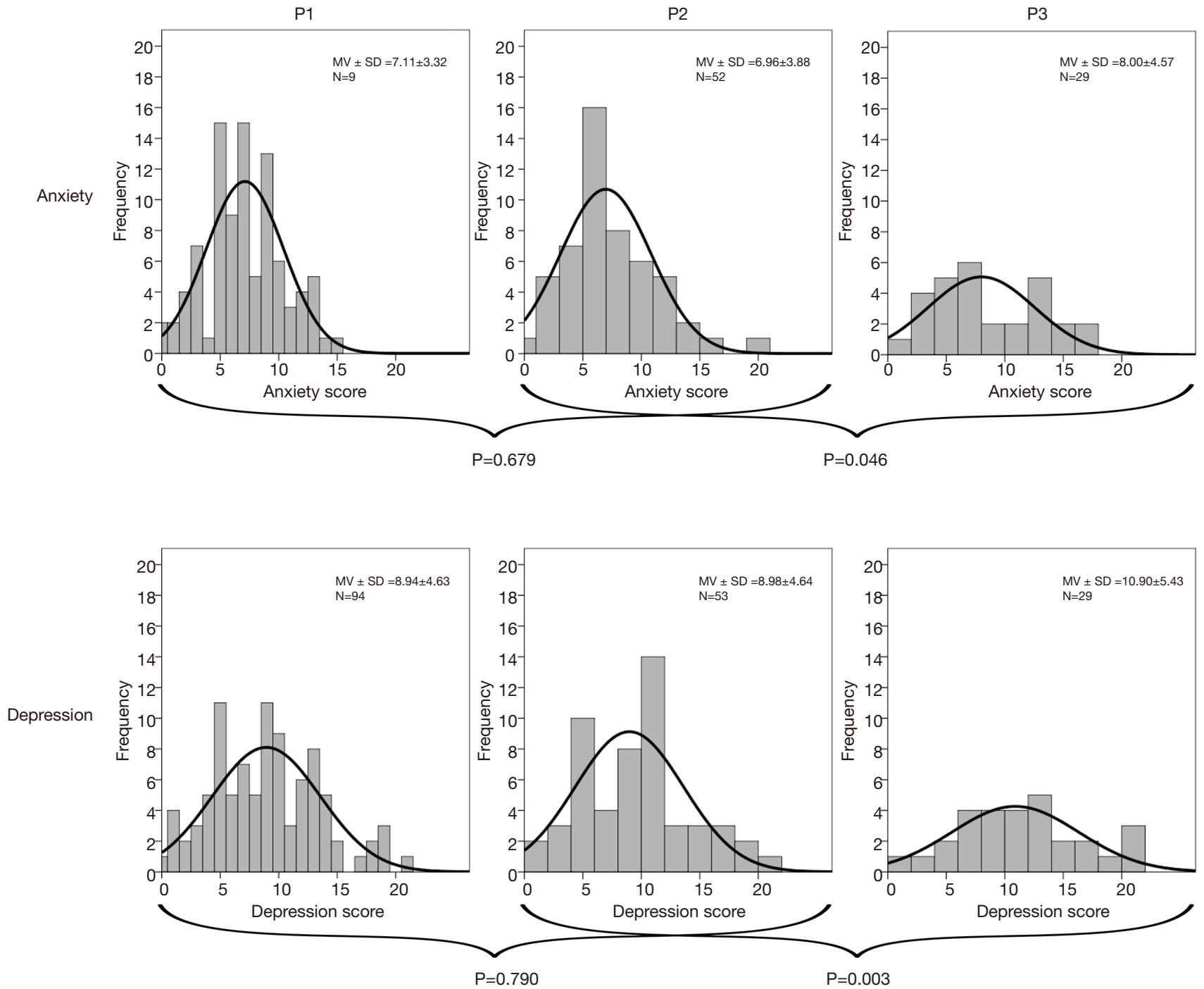

Figure 2 HADS-D sum scores according to time points. The HADS-D consists of two subscales, one for symptoms of anxiety and one for symptoms of depression. Subscale scores range from 0 , indicating no distress, to 21 , indicating maximum distress; a score $\geq 8$ indicates clinically meaningful anxiety or depression. Numbers for each score are displayed. Significance analyses between time points (P1 vs. P2; P2 vs. P3) are shown.

Table 2 Longitudinal comparison: mean values of HADS-D subscales

\begin{tabular}{lcccc}
\hline Score & P1 & P2 & P3 & $\begin{array}{c}\text { P1-P2 } \\
\text { P value }\end{array}$ \\
\hline Anxiety (N) & 27 & 27 & 27 & 0.046 \\
PV value & & 0.871 \\
Median (min - max) & $6.29 \pm 2.89$ & $6.33 \pm 3.35$ & $7.85 \pm 4.61$ & $7[1-17]$ \\
Depression (N) & $6[2-12]$ & $6[0-14]$ & 27 & 0.779 \\
MV \pm SD & 27 & 27 & $11.11 \pm 5.46$ & 0.003 \\
Median (min - max) & $8.32 \pm 4.48$ & $8.54 \pm 4.52$ & $10[1-21]$ & \\
\hline
\end{tabular}




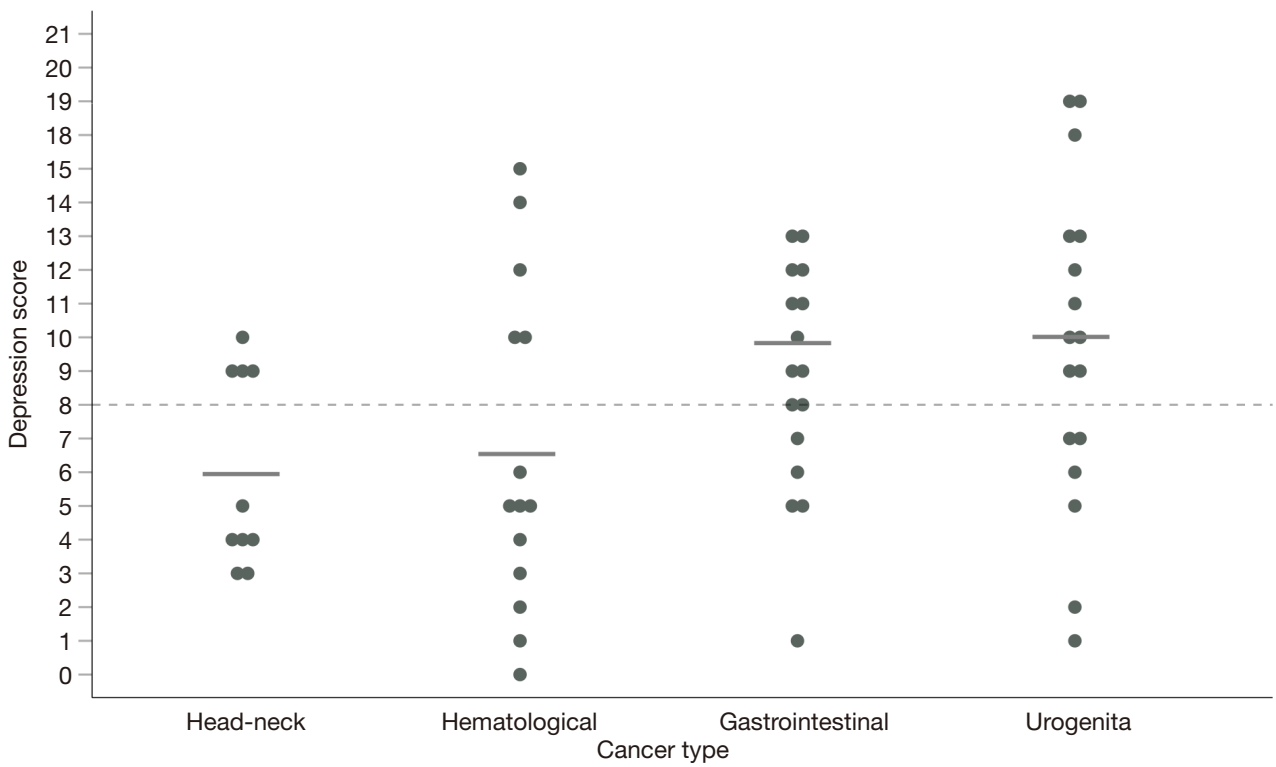

Figure 3 Depression scale (HADS-D/D) at admission. Individual depression scores on admission to PCU are shown according to the underlying cancer type. The mean values (solid bars) and the HADS cut-off (dashed line) are displayed. PCU, palliative care unit.

Table 3 Mean values of HADS-D for cancer patients depending on time from initial diagnosis

\begin{tabular}{|c|c|c|c|c|c|}
\hline Score & $\begin{array}{c}\mathrm{P} 1 \\
\mathrm{MV} \pm \mathrm{SD}\end{array}$ & $\begin{array}{c}\mathrm{P} 2 \\
\mathrm{MV} \pm \mathrm{SD}\end{array}$ & $\begin{array}{c}\mathrm{P} 3 \\
\mathrm{MV} \pm \mathrm{SD}\end{array}$ & $\begin{array}{l}\mathrm{P} 1-\mathrm{P} 2 \\
\mathrm{P} \text { value }\end{array}$ & $\begin{array}{l}\text { P2-P3 } \\
\text { P value }\end{array}$ \\
\hline \multicolumn{6}{|l|}{ Anxiety } \\
\hline$<365$ days & $7.95 \pm 3.42$ & $8.06 \pm 4.35$ & $10.00 \pm 4.97$ & 0.900 & 0.172 \\
\hline$P$ value & 0.031 & 0.114 & 0.060 & & \\
\hline$\geq 365$ days & $8.05 \pm 4.47$ & $8.56 \pm 4.47$ & $8.92 \pm 5.25$ & 0.382 & 0.022 \\
\hline$<365$ days & $10.16 \pm 4.75$ & $10.67 \pm 4.86$ & $13.60 \pm 4.79$ & 0.732 & 0.256 \\
\hline$P$ value & 0.036 & 0.141 & 0.037 & & \\
\hline \multicolumn{6}{|l|}{ Global score } \\
\hline$P$ value & 0.008 & 0.162 & 0.040 & & \\
\hline
\end{tabular}

$\geq$ initial diagnosis 365 days ago or longer ( $P 1: \mathrm{N}=43$. $\mathrm{P} 2: \mathrm{N}=27$. $\mathrm{P} 3: \mathrm{N}=13)$; < initial diagnosis less than 365 days ago ( $\mathrm{P} 1: \mathrm{N}=43$. $\mathrm{P} 2: \mathrm{N}=18$. P3: $\mathrm{N}=10$ ).

of younger and older patients. However, the significant deterioration from discharge to two weeks afterward was only found among patients with higher age $(>65)$. This was true for anxiety $(\mathrm{P}=0.021)$ and for depression $(\mathrm{P}=0.010)$ scores (Table S5).

The same findings were made regarding the ECOG performance status. A higher ECOG score at admission led to a more likely deterioration of anxiety $(\mathrm{P}=0.047)$ 
and depression $(\mathrm{P}=0.006)$ at home (Table S6). However, a high ECOG score did not correlate with higher age $>65$ $(\mathrm{P}=0.268)$.

\section{Discussion}

Here, we present the first study screening longitudinally for anxiety and depressive symptoms in a German PC cancer patient cohort at three different time points: at admission to a PCU, at discharge, and two weeks after discharge. Using the HADS-D scores, it was demonstrated that anxiety and depressive symptoms were prevalent in this cohort at unrecognized high levels. Very importantly we could identify that anxiety and depressive symptoms worsened shortly after discharge. To our knowledge no other study has measured this effect thus far.

At admission to PCU $41 \%$ of the 94 patients had clinically meaningful anxiety and $57 \%$ had relevant depression scores, demonstrating the high prevalence. Consequently, anxiety levels were lower than depression levels. These results are in line with other studies: Holtom and Barraclough [2000] state that in PC patients, anxiety is less frequent than depression. They found depression in $56 \%$ of patients, of whom $28 \%$ had relevant anxiety levels (18). Renom-Guiteras et al. screened prospectively in $61 \mathrm{PC}$ cancer inpatients and showed a depression level of $62 \%$ and an anxiety level of 54\% (25). Another study of Teunissen et al. showed possible depression in $56 \%$ and possible anxiety in $34 \%$ of 79 hospitalized advanced cancer patients (6). Bužgová et al. studied 225 cancer patients receiving $\mathrm{PC}$ in an oncology department and found anxiety to be present in $34 \%$ and depression in $48 \%$ of patients (9). In contrast, Austin et al. [2011] found anxiety and depression in only $20 \%$ of PC patients without significant difference between $\mathrm{PC}$ inpatients and those receiving PC at home (4).

Of note, underlying cancer disease significantly influenced depression scores. Whereas hematological and head-neck cancer patients had lower depression scores, gastrointestinal and urogenital cancer patients had higher depression scores, at least at admission. There were no differences in regards to anxiety, although patient numbers were low. It can be stated that each patient population has specific needs. This has been shown in a randomized clinical trial by Temel et al. (26) amongst other studies. In their study, early integrated PC improved QOL and mood in patients with incurable cancers but patient outcomes varied by cancer type. In addition, a meta-analysis revealed that there is a high prevalence of anxiety and depressive symptoms in men with prostate cancer (27) pointing as well at the need for support of these patients.

At discharge, anxiety levels had slightly improved and depression scores remained at the same high level. These data indicate that anxiety and depressive symptoms can be stabilized during a PCU visit. In contrast, Bužgová et al. measured a significant deterioration in advanced cancer patients overtime during inpatient stay. This study was conducted in an oncology department whereas our study took place in a PCU. In interventional studies, depression scores could be improved by integrated inpatient PC (additional to transplant care) and aromatherapy massage in a hospice setting $(28,29)$.

One of the most important findings of PaRoLi study is the fact that following discharge anxiety and depressive symptoms deteriorate significantly after short period of time. Studies by Lloyd-Williams et al. have shown that in an outpatient setting PC cancer patient depression scores remain largely stable $(15,30)$. Other outpatient PC studies showed lower HADS scores $(4,23,31)$. However, these patients were mostly early PC patients. To our knowledge, no other non-interventional study has analyzed psychological distress in a PC cohort longitudinally after discharge home. Whereas for cancer patients no specialized outpatient teams exist, this is the case for PC. In Germany, specialized outpatient PC teams exist consisting of nurses and doctors visiting patients at home to alleviate symptom burden. Our study was not powered to detect beneficial effects of SOPC and due to low numbers we couldn't detect differences in patients receiving SOPC. Other studies showed beneficial effects of SOPC (not focusing on depression) (32). More research is needed to study the effect of SOPC on psychological distress.

Performing studies in a PC patient cohort is very difficult due to the medical conditions of the patients in this situation. The recruitment of study individuals from a limited number of often severely burdened patients in end of life care is a major challenge. Almost $15 \%$ of the palliative patients died within 24 hours after admission. Due to this vulnerability, we decided to screen only with HADS-D for anxiety and depression. The PaRoLi study was a non-randomized, single-center prospective study. Nevertheless, a large, consecutive patient number was screened-representing an unselected PC inpatient cohort. Participants of our study were almost exclusively advanced cancer patients. This corresponds to other PC studies (4,18,25). Moreover, data from the German 
Hospice and Palliative Care Evaluation, a national longterm quality assurance project providing information on PC patients, showed that $92 \%$ of PC patients in Germany suffer from cancer (33). So, our study cohort can be seen as representative for a German PC cohort.

The overall participation rate was $49.5 \%$. Other prospective studies in $\mathrm{PC}$ report participation rates ranging from $28 \%$ to $74 \%(25,34-36)$. As expected, participation decreased over time due to quickly deteriorating functional status, pointing at the difficulties to perform longitudinal studies in a PC cohort. About one third of the patients died during PC stay. A limitation is the selection bias. Many patients stopped participating or refused initially to participate due to fatigue or pain. There was no assessment, when these patients got better during inpatient stay, because later enrollment was not part of the protocol. Thus, the overall picture may even be too positive. This bias may be circumvented by multiple study enrollments in subsequent studies.

\section{Conclusions}

In essence, our study points out that discharge and the time after discharge are crucial for the patients and interventions may have to be explored. This observation was particularly pronounced in patients with recent cancer diagnosis being probably still in the process of coping. Other negatively influencing factors were poor performance score and higher age. Our results integrate into existing data and demonstrate that patients with progressed disease often suffer from anxiety and depressive symptoms.

In conclusion, the PaRoLi study adds important aspects of incurable cancer patient care. Anxiety and depressive symptoms should be screened for regularly in all PC patients, in particular after discharge from an inpatient setting. Future studies will have to address the potential beneficial effects of discharge.

\section{Acknowledgments}

First and foremost, we thank the patients who participated in this study. Moreover, we would like to express our gratitude to all staff of the palliative care unit of Rostock University Medical Center for their dedicated work and their ongoing willingness to help within this project.

Funding: None.

\section{Footnote}

Reporting Checklist: The authors have completed the STROBE reporting checklist. Available at http://dx.doi. org/10.21037/apm-20-1346

Data Sharing Statement: Available at http://dx.doi. org/10.21037/apm-20-1346

Conflicts of Interest: All authors have completed the ICMJE uniform disclosure form (available at http://dx.doi. org/10.21037/apm-20-1346). CJ serves as an unpaid editorial board member of Annals of Palliative Medicine from Jan 2019 to Dec 2021. The other authors have no conflicts of interest to declare.

Etbical Statement: The authors are accountable for all aspects of the work in ensuring that questions related to the accuracy or integrity of any part of the work are appropriately investigated and resolved. The study was conducted in accordance with the Declaration of Helsinki (as revised in 2013). The study was approved by institutional ethics board of Rostock University Medical Center, Germany (No.: A 2013-0028) and informed consent was taken from all the patients.

Open Access Statement: This is an Open Access article distributed in accordance with the Creative Commons Attribution-NonCommercial-NoDerivs 4.0 International License (CC BY-NC-ND 4.0), which permits the noncommercial replication and distribution of the article with the strict proviso that no changes or edits are made and the original work is properly cited (including links to both the formal publication through the relevant DOI and the license). See: https://creativecommons.org/licenses/by-nc-nd/4.0/.

\section{References}

1. Block SD. Assessing and managing depression in the terminally ill patient. ACP-ASIM End-of-Life Care Consensus Panel. American College of Physicians American Society of Internal Medicine. Ann Intern Med 2000;132:209-18.

2. Morasso G, Capelli M, Viterbori P, et al. Psychological and symptom distress in terminal cancer patients with met and unmet needs. J Pain Symptom Manage 1999;17:402-9.

3. Gruneir A, Smith TF, Hirdes J, et al. Depression in 
patients with advanced illness: an examination of Ontario complex continuing care using the Minimum Data Set 2.0. Palliat Support Care 2005;3:99-105.

4. Austin P, Wiley S, McEvoy PM, et al. Depression and anxiety in palliative care inpatients compared with those receiving palliative care at home. Palliat Support Care 2011;9:393-400.

5. Delgado-Guay M, Parsons HA, Li Z, et al. Symptom distress in advanced cancer patients with anxiety and depression in the palliative care setting. Support Care Cancer 2009;17:573-9.

6. Teunissen SCCM, Graeff A, Voest EE, et al. Are anxiety and depressed mood related to physical symptom burden? A study in hospitalized advanced cancer patients. Palliat Med 2007;21:341-6.

7. Hotopf M, Chidgey J, Addington-Hall J, et al. Depression in advanced disease: A systematic review. Part 1: Prevalence and case finding. Palliat Med 2002;16:81-97.

8. Smith EM, Gomm SA, Dickens CM. Assessing the independent contribution to quality of life from anxiety and depression in patients with advanced cancer. Palliat Med 2003;17:509-13.

9. Bužgová R, Jarošová D, Hajnová E. Assessing anxiety and depression with respect to the quality of life in cancer inpatients receiving palliative care. Eur J Oncol Nurs 2015;19:667-72.

10. Miovic M, Block S. Psychiatric disorders in advanced cancer. Cancer 2007;110:1665-76.

11. Burcusa SL, Iacono WG. Risk for recurrence in depression. Clin Psychol Rev 2007;27:959-85.

12. Rodin G, Walsh A, Zimmermann C, et al. The contribution of attachment security and social support to depressive symptoms in patients with metastatic cancer. Psychooncology 2007;16:1080-91.

13. Lo C, Zimmermann C, Rydall A, et al. Longitudinal study of depressive symptoms in patients with metastatic gastrointestinal and lung cancer. J Clin Oncol 2010;28:3084-9.

14. Rayner L, Lee W, Price A, et al. The clinical epidemiology of depression in palliative care and the predictive value of somatic symptoms: cross-sectional survey with four-week follow-up. Palliat Med 2011;25:229-41.

15. Lloyd-Williams M, Shiels C, Taylor F, et al. Depression-an independent predictor of early death in patients with advanced cancer. J Affect Disord 2009;113:127-32.

16. Irwin SA, Rao $\mathrm{S}$, Bower $\mathrm{K}$, et al. Psychiatric issues in palliative care: recognition of depression in patients enrolled in hospice care. J Palliat Med 2008;11:158-63.
17. Zigmond AS, Snaith RP. The Hospital Anxiety and Depression Scale. Acta Psychiatr Scand 1983;67:361-70.

18. Holtom N, Barraclough J. Is the Hospital Anxiety and Depression Scale (HADS) useful in assessing depression in palliative care? Palliat Med 2000;14:219-20.

19. Lloyd-Williams M. Screening for depression in palliative care patients: a review. Eur J Cancer Care (Engl) 2001;10:31-5.

20. Mitchell AJ, Meader N, Symonds P. Diagnostic validity of the Hospital Anxiety and Depression Scale (HADS) in cancer and palliative settings: a meta-analysis. J Affect Disord 2010;126:335-48.

21. Herrmann-Lingen C, Buss U, Snaith RP. Hospital Anxiety and Depression Scale - Deutsche Version (HADS-D) (3., aktualisierte und neu normierte Aufl.). Bern: Verlag Hans Huber, 2011.

22. von Elm E, Altman DG, Egger M, et al. The Strengthening the Reporting of Observational Studies in Epidemiology (STROBE) statement: guidelines for reporting observational studies. J Clin Epidemiol 2008;61:344-9.

23. Temel JS, Greer JA, Muzikansky A, et al. Early palliative care for patients with metastatic non-small-cell lung cancer. N Engl J Med 2010;363:733-42.

24. Bjelland I, Dahl AA, Haug TT, et al. The validity of the Hospital Anxiety and Depression Scale. An updated literature review. J Psychosom Res 2002;52:69-77.

25. Renom-Guiteras A, Planas J, Farriols C, et al. Insomnia among patients with advanced disease during admission in a Palliative Care Unit: a prospective observational study on its frequency and association with psychological, physical and environmental factors. BMC Palliat Care 2014;13:40.

26. Temel JS, Greer JA, El-Jawahri A, et al. Effects of Early Integrated Palliative Care in Patients With Lung and GI Cancer: A Randomized Clinical Trial. J Clin Oncol 2017;35:834-41.

27. Watts S, Leydon G, Birch B, et al. Depression and anxiety in prostate cancer: a systematic review and meta-analysis of prevalence rates. BMJ Open 2014;4:e003901.

28. El-Jawahri A, Traeger L, Greer JA, et al. Effect of Inpatient Palliative Care During Hematopoietic StemCell Transplant on Psychological Distress 6 Months After Transplant: Results of a Randomized Clinical Trial. J Clin Oncol 2017;35:3714-21.

29. Soden K, Vincent K, Craske S, et al. A randomized controlled trial of aromatherapy massage in a hospice setting. Palliat Med 2004;18:87-92.

30. Lloyd-Williams M, Riddleston H. The Stability of 
Depression Scores in Patients Who Are Receiving Palliative Care. J Pain Symptom Manage 2002;24:593-7.

31. Götze H, Brähler E, Gansera L, et al. Psychological distress and quality of life of palliative cancer patients and their caring relatives during home care. Support Care Cancer 2014;22:2775-82.

32. Groh G, Vyhnalek B, Feddersen B, et al. Effectiveness of a specialized outpatient palliative care service as experienced by patients and caregivers. J Palliat Med 2013;16:848-56.

33. Hess S, Stiel S, Hofmann S, et al. Trends in specialized palliative care for non-cancer patients in Germany--data from the national hospice and palliative care evaluation (HOPE). Eur J Intern Med 2014;25:187-92.

Cite this article as: Sewtz C, Muscheites W, Grosse-Thie C, Kriesen U, Leithaeuser M, Glaeser D, Hansen P, Kundt G, Fuellen G, Junghanss C. Longitudinal observation of anxiety and depression among palliative care cancer patients. Ann Palliat Med 2021;10(4):3836-3846. doi: 10.21037/apm-20-1346
34. Minagawa H, Uchitomi Y, Yamawaki S, et al. Psychiatric morbidity in terminally ill cancer patients: a prospective study. Cancer 1996;78:1131-7.

35. Le Fevre P, Devereux J, Lawrie SM, et al. Screening for psychiatric illness in the palliative care inpatient setting: a comparison between the Hospital Anxiety and Depression Scale and the General Health Questionnaire-12. Palliat Med 1999;13:399-407.

36. Bakitas M, Lyons KD, Hegel MT, et al. Effects of a palliative care intervention on clinical outcomes in patients with advanced cancer: the Project ENABLE II randomized controlled trial. JAMA 2009;302:741-9. 


\section{Supplementary}

Table S1 Longitudinal comparison: mean values of HADS-D subscales (all questionnaires)

\begin{tabular}{|c|c|c|c|c|c|}
\hline & $\mathrm{P} 1$ & $\mathrm{P} 2$ & P3 & P1-P2 & P2-P3 \\
\hline Anxiety (N) & (93) & (52) & (29) & & \\
\hline $\mathrm{MV} \pm \mathrm{SD}$ & $7.11 \pm 3.32$ & $6.96 \pm 3.88$ & $8.00 \pm 4.57$ & 0.679 & 0.046 \\
\hline median ( $\min -\max )$ & $7(0-15)$ & $6(0-19)$ & $7(1-17)$ & & \\
\hline $\mathrm{MV} \pm \mathrm{SD}$ & $8.94 \pm 4.63$ & $8.98 \pm 4.64$ & $10.90 \pm 5.43$ & 0.790 & 0.003 \\
\hline Median (min- $\max )$ & $9(0-21)$ & $9(1-21)$ & $10(1-21)$ & & \\
\hline Global score $(\mathrm{N})$ & (93) & (52) & (29) & & \\
\hline $\mathrm{MV} \pm \mathrm{SD}$ & $16.03 \pm 6.64$ & $15.92 \pm 7.67$ & $18.90 \pm 9.66$ & 0.950 & 0.005 \\
\hline
\end{tabular}

Table S2 Symptom burden at each time point

\begin{tabular}{lccc}
\hline Score & P1 & P2 & P3 \\
\hline Anxiety $\geq 11-$ no. (\%) & $14(15.1 \%)$ & $9(17.3 \%)$ & $9(31.0 \%)$ \\
Depression $\geq 11-$ no. (\%) & $31(33.0 \%)$ & $18(34.0 \%)$ & $13(44.8 \%)$ \\
Anxiety or depression $\geq 11-$ no. (\%) & $34(36.2 \%)$ & $21(39.6 \%)$ & $13(44.8 \%)$ \\
Anxiety $\geq 8-$ no. (\%) & $38(40.9 \%)$ & $19(36.5 \%)$ & $13(44.8 \%)$ \\
Depression $\geq 8-$ no. (\%) & $56(59.6 \%)$ & $34(64.2 \%)$ & $21(72.4 \%)$ \\
Anxiety or depression $\geq 8-$ no. (\%) & $65(69.1 \%)$ & $36(67.9 \%)$ & $21(72.4 \%)$ \\
\hline
\end{tabular}

Table S3 HADS-D depression scale according to cancer type

\begin{tabular}{lcc}
\hline Cancer localization & Number $(\mathrm{N})$ & Depression score at admission to PCU (MV \pm SD) \\
\hline Head-neck-cancer & 10 & $6.00 \pm 2.87$ \\
Hematological cancer & 14 & $6.57 \pm 4.82$ \\
Gastrointestinal cancer & 15 & $9.93 \pm 4.43$ \\
Urogenital cancer & 17 & $10.06 \pm 5.33$ \\
\hline
\end{tabular}


Table S4 HADS-D scores depending on the length of stay in the PCU

\begin{tabular}{|c|c|c|c|c|c|}
\hline Score & $\mathrm{P} 1$ & $\mathrm{P} 2$ & P3 & P1-P2 & P2-P3 \\
\hline \multicolumn{6}{|l|}{ Anxiety } \\
\hline $\mathrm{PCU} \leq 7$ & $7.42 \pm 3.17$ & $6.57 \pm 2.50$ & $9.44 \pm 4.50$ & 0.277 & 0.059 \\
\hline $\mathrm{PCU}>7$ & $6.74 \pm 3.48$ & $7.28 \pm 4.72$ & $6.23 \pm 4.15$ & 0.688 & 0.372 \\
\hline \multicolumn{6}{|l|}{ Depression } \\
\hline $\mathrm{PCU} \leq 7$ & $8.90 \pm 3.96$ & $10.21 \pm 3.82$ & $12.81 \pm 4.40$ & 0.443 & 0.047 \\
\hline $\mathrm{PCU}>7$ & $8.98 \pm 5.33$ & $7.97 \pm 5.05$ & $8.54 \pm 5.80$ & 0.805 & 0.023 \\
\hline P-value & 0.936 & 0.079 & 0.032 & & \\
\hline $\mathrm{PCU}>7$ & $15.70 \pm 7.40$ & $15.24 \pm 8.98$ & $14.77 \pm 9.53$ & 0.959 & 0.090 \\
\hline P-value & 0.655 & 0.477 & 0.038 & & \\
\hline
\end{tabular}

Table S5 HADS-D scores depending on age

\begin{tabular}{|c|c|c|c|c|c|}
\hline Score & $\mathrm{P} 1$ & P2 & P3 & P1-P2 & P2-P3 \\
\hline \multicolumn{6}{|l|}{ Anxiety } \\
\hline$\leq 65$ & $7.63 \pm 3.28$ & $7.68 \pm 3.42$ & $7.82 \pm 4.58$ & 0.429 & 0.865 \\
\hline$>65$ & $6.75 \pm 3.32$ & $6.55 \pm 4.12$ & $8.11 \pm 4.69$ & 0.929 & 0.021 \\
\hline \multicolumn{6}{|c|}{ Depression } \\
\hline$\leq 65$ & $8.24 \pm 4.68$ & $8.85 \pm 4.48$ & $9.91 \pm 6.46$ & 0.593 & 0.169 \\
\hline$>65$ & $9.41 \pm 4.57$ & $9.06 \pm 4.80$ & $11.50 \pm 4.79$ & 0.969 & 0.010 \\
\hline P-value & 0.232 & 0.874 & 0.454 & & \\
\hline$>65$ & $16.15 \pm 6.75$ & $15.61 \pm 7.94$ & $19.61 \pm 9.17$ & 0.892 & 0.004 \\
\hline P-value & 0.844 & 0.693 & 0.619 & & \\
\hline
\end{tabular}

$\leq 65$ years or younger $(P 1: N=38 . P 2: N=19 . P 3: N=11)$; > older than 65 years $(P 1: N=55 . P 2: N=33 . P 3: N=18)$ 
Table S6 HADS-D scores depending on ECOG performance status

\begin{tabular}{|c|c|c|c|c|c|}
\hline Score & P1 & P2 & P3 & P1-P2 & P2-P3 \\
\hline \multicolumn{6}{|l|}{ Anxiety } \\
\hline ECOG 1-2 & $6.41 \pm 3.00$ & $6.38 \pm 3.29$ & $7.27 \pm 4.41$ & 0.526 & 0.473 \\
\hline ECOG 3-4 & $7.48 \pm 3.43$ & $7.35 \pm 4.24$ & $8.44 \pm 4.73$ & 0.241 & 0.047 \\
\hline \multicolumn{6}{|l|}{ Depression } \\
\hline ECOG 1-2 & $8.53 \pm 4.95$ & $9.09 \pm 4.59$ & $9.00 \pm 4.54$ & 0.853 & 0.276 \\
\hline ECOG 3-4 & $9.15 \pm 4.48$ & $8.90 \pm 4.74$ & $12.06 \pm 5.71$ & 0.578 & 0.006 \\
\hline P-value & 0.545 & 0.886 & 0.144 & & \\
\hline ECOG 3-4 & $16.61 \pm 6.45$ & $16.26 \pm 8.23$ & $20.50 \pm 10.08$ & 0.809 & 0.011 \\
\hline P-value & 0.251 & 0.706 & 0.260 & & \\
\hline
\end{tabular}

ECOG 1 or $2(P 1: N=32 . P 2: N=21 . P 3: N=11)$; ECOG 3 or $4(P 1: N=61 . P 2: N=31 . P 3: N=18)$ 